\title{
LÝ THUYẾT VÀ THỰC TÊ ÁP DỤNG MÔ HÌNH 5S: TRƯờNG HợP DƯ ÁN JICA-IUH TẠI TRƯờNG Đ̣̇I HỌC CÔNG NGHIỆP TP.HCM
}

\author{
NGUYỄN QUANG VINH \\ Trường Đại học Công nghiệp thành phố Hồ Chí Minh \\ nguyenquangvinh@iuh.edu.vn
}

Tóm tắt: Dự án Phát triển nguồn nhân lực ngành hóa chất - công nghiệp nặng tại Trường Đại học Công nghiệp thành phố Hồ Chí Minh (IUH) (gọi tắt là Dự án JICA-IUH) được bắt đầu triển khai từ cuối năm 2013. Cơ sở Thanh Hóa, Khoa Công nghệ Hóa học và Khoa Công nghệ Cơ khí tại cơ sở chính ở thành phố

Hồ Chí Minh là ba đơn vị đầu tiên triển khai thực hiện. Bài viết trình bày lý thuyết cơ bản và thực tế áp dụng $5 \mathrm{~S}$ trong quá trình triển khai thực hiện Dự án tại IUH. Nội dung được tổng hợp từ các tài liệu hướng dẫn, các ý kiến nhận xét của chuyên gia Nhật Bản và từ các báo cáo thực hiện Dự án của ba đơn vị thụ hưởng Dự án JICA-IUH trên.

Từ khóa: 5S, dự án JICA-IUH, mô hình đào tạo Kosen

\section{S THEORY AND PRACTICE: THE CASE OF JICA-IUH PROJECT AT INDUSTRIAL UNIVERSITY OF HO CHI MINH CITY}

\begin{abstract}
The Project Human Resources Development for Heavy-chemical Industry at Industrial University of Ho Chi Minh City (IUH) (JICA-IUH Project) was initiated by the end of 2013. The Thanh Hoa campus, the Faculty of Chemical Engineering, and the Faculty of Mechanical Engineering in Ho Chi Minh city campus implemented the Project as the first three recipients. This paper presents 5S theory and practice applied in the project implementation at IUH. Data were from guidance documents, Japanese experts' comments, and reports on project implementation from the three ones.
\end{abstract}

Keywords: 5S, JICA-IUH project, Kosen education model

\section{1 ĐặT VẤN ĐỀ}

Yếu tố nhân lực, cùng với đó là nội dung giáo dục và đào tạo, luôn đóng một vai trò quan trọng trong sự phát triển của bất kỳ tổ chức hay quốc gia nào. Dự án Phát triển nguồn nhân lực ngành hóa chất - công nghiệp nặng tại Trường Đại học Công nghiệp thành phố Hồ Chí Minh (gọi tắt là Dự án JICA-IUH) được bắt đầu triển khai từ cuối năm 2013, trong đó cơ sở Thanh Hóa, Khoa Công nghệ Hóa học và Khoa Công nghệ Cơ khí tại cơ sở chính ở thành phố Hồ Chí Minh là ba đơn vị đầu tiên triển khai thực hiện. Dự án nhằm áp dụng mô hình đào tạo Kosen của Nhật Bản tại trường trong đó tập trung vào ba nội dung chính là (1) Áp dụng 5S, (2) Đổi mới phương pháp giảng dạy theo mô hình $\mathrm{PBL}$, và (3) Hoạt động kết nối doanh nghiệp. Bài viết này trình bày lý thuyết cơ bản và thực tế áp dụng $5 \mathrm{~S}$ trong quá trình triển khai thực hiện Dự án tại IUH. Nội dung được tổng hợp từ các tài liệu hướng dẫn, các ý kiến nhận xét của chuyên gia Nhật Bản và từ các báo cáo thực hiện Dự án của ba đơn vị thụ hưởng Dự án JICA-IUH trên.

\section{NỘI DUNG CƠ BẢN VÈ $5 S$}

\subsection{Triết lý $5 \mathrm{~S}$}

5S là một trong ba nội dung chính của Mô hình đào tạo Kosen, bên cạnh nội dung về phương pháp giảng dạy PBL (Problem-based Learning) và Kết nối doanh nghiệp. $5 \mathrm{~S}$ cũng được coi như là một phương pháp quản lí nhằm mục đích sắp xếp nơi làm việc hay học tập một cách khoa học hướng đến mục đích cuối cùng là nâng cao hiệu quả công việc trong một môi trường làm việc thoải mái, thân thiện và không 
ảnh hưởng đến sức khỏe. Thực hiện tốt $5 \mathrm{~S}$ đồng thời cũng giúp nâng cao hình ảnh của tổ chức đối với khách hàng, cộng đồng, và xã hội cũng như với đối tác của tổ chức.

Thành công của việc thực hiện $5 \mathrm{~S}$ liên quan đến rất nhiều yếu tố: từ quyết tâm của lãnh đạo, ý thức và sự tự giác của các cá nhân, đến phương pháp thực hiện, và cả sự phối hợp giữa các đơn vị trong cùng một tổ chức, v.v... Bên cạnh đó, không thể không nói đến vai trò quan trọng của các chuyên gia, đặc biệt là các chuyên gia đến từ Nhật Bản, cái nôi của $5 \mathrm{~S}$.

Sự quyết tâm của lãnh đạo là một trong những yếu tố quan trọng đầu tiên ảnh hưởng đến thành công của hoạt động $5 \mathrm{~S}$. Hơn ai hết, đầu tiên, lãnh đạo phải hành xử sao cho nhân viên có thể coi đấy như là một tấm gương để noi theo. Sự quyết tâm không chỉ thể hiện trên giấy tờ thông qua các quyết định, quy định ban hành, mà còn phải được cụ thể hóa thông qua các biện pháp chế tài hay khen thưởng - động viên cụ thể và thực tế. Trong $5 \mathrm{~S}$, nội dung Sẵn sàng liên quan đến việc duy trì và tiếp tục phát huy những thành quả đã đạt được từ các nội dung $4 \mathrm{~S}$ trước đó. Do đó, lãnh đạo cũng cần phải thường xuyên quan tâm và luôn "Sẵn sàng" cho công tác này.

Vai trò của cá nhân trong thực hiện $5 \mathrm{~S}$ ở tổ chức vô cùng quan trọng. Sự thành công của tập thể trong thực hiện $5 \mathrm{~S}$ dựa hoàn toàn vào ý thức và sự tự giác của mỗi cá nhân. $5 \mathrm{~S}$ không phải là một thứ quá khó khăn, không thể không thực hiện được. $5 \mathrm{~S}$ trước hết chính là việc mỗi cá nhân tự mình xác định được, kiểm soát được, và thực hiện được các hoạt động phân loại, sắp xếp, làm sạch vật dụng tại nơi mình đang làm việc. Cũng có thể coi đây là một hoạt động tu dưỡng bản thân, thể hiện tinh thần trách nhiệm cá nhân đối với tập thể nơi mình đang công tác. Trong phạm vi trường học, cá nhân không chỉ là giảng viên, công chức viên chức mà còn là sinh viên, học viên đang tham gia các hoạt động đào tạo và nghiên cứu trong nhà trường. Ý thức tuân thủ theo các nội dung $5 \mathrm{~S}$ cũng đồng thời thể hiện ý thức tuân thủ kỷ cương nề nếp của cá nhân đối với tổ chức.

Quá trình thực hiện $5 \mathrm{~S}$ có thể coi là một quá trình cải tiến liên tục, trong đó, phương pháp vòng lặp PDCA được áp dụng một cách xuyên suốt: $\mathrm{P}$ (Plan) lập kế hoạch hành động chi tiết, xây dựng các mục tiêu cụ thể, thời gian biểu thực hiện, phân công trách nhiệm và công việc; $\mathrm{D}(D o)$ triển khai các hoạt động đúng theo kế hoạch đã đề ra với việc phân bổ các nguồn lực và nguồn tài nguyên thực hiện; $\mathrm{C}$ (Check) kiểm tra các hoạt động đã thực hiện so với kế hoạch và đánh giá kết quả đạt được so với các mục tiêu đặt ra lúc đầu; và $\mathrm{A}(A c t)$ điều chỉnh các hoạt động đã thực hiện sao cho đúng với như kế hoạch đã đặt ra ban đầu, và sau đó, có thể đưa ra những hướng đi mới cho nội dung kế hoạch được xây dựng tiếp theo.

Một tổ chức dĩ nhiên sẽ là một tập hợp các thành phần liên kết hữu cơ với nhau trong một hệ thống mang tính đặc thù riêng. $5 \mathrm{~S}$ không phải là nhiệm vụ của riêng ban lãnh đạo hay của riêng một đơn vị. Nếu chỉ có một đơn vị trong tổ chức làm tốt $5 \mathrm{~S}$ mà các đơn vị khác không thực hiện thì kết quả đạt được không mang nhiều ý nghĩa đối với toàn bộ tổ chức. Trong giai đoạn đầu thực hiện $5 \mathrm{~S}$, một hay một số đơn vị có thể được chọn ra để thực hiện thí điểm, nhưng sau đó, $5 \mathrm{~S}$ cần nên được triển khai áp dụng cho toàn bộ tổ chức. Tính thống nhất trong các hoạt động $5 \mathrm{~S}$ sẽ ảnh hưởng tích cực đến tính thống nhất trong các hoạt động khác. Điều này sẽ tạo nên một sức mạnh mới cho tổ chức.

Trong thực tế áp dụng, nội dung liên quan đến $5 \mathrm{~S}$ rất đa dạng. Các chuyên gia Nhật Bản, bên cạnh kiến thức cơ bản về $5 \mathrm{~S}$, còn tư vấn kinh nghiệm thực tế áp dụng và đánh giá hoạt động $5 \mathrm{~S}$ tại các tổ chức trước đây. Không có một bộ tiêu chuẩn riêng hay duy nhất nào được các chuyên gia sử dụng để đánh giá kết quả thực hiện $5 \mathrm{~S}$. Câu hỏi thường được các chuyên gia hay dùng khi kiểm tra đánh giá $5 \mathrm{~S}$ rất đơn giản: “Thứ này có cần thiết hay không?”. Tính logic của vấn đề ở chỗ: Một vật dụng nếu thường xuyên sử dụng hay thường xuyên được người dùng quan tâm, chắc chắn sẽ không có chuyện có bụi bám đầy.

Trong thực hiện $5 \mathrm{~S}$ sẽ không có chỗ cho các câu trả lời không biết hay không rõ. Không chỉ người quản lý mà ngay cả nhân viên cũng cần phải nắm được (nếu không thì phải tìm hiểu) lý do tồn tại của những vật dụng hay máy móc thiết bị không cần thiết hoặc thực sự không cần thiết nhưng vẫn hiện diện tại nơi làm việc dù trong thời gian ngắn. Bên cạnh đó, $5 \mathrm{~S}$ không chỉ thực hiện trong phạm vi không gian nội bộ trong phòng thuộc đơn vị mà còn thực hiện đối với cả các khu vực chung, công cộng trong tổ chức. Có thể một đơn vị trong tổ chức sẽ chịu trách nhiệm chính trong công tác $5 \mathrm{~S}$ liên quan đến các vị trí công cộng, tuy nhiên, các cá nhân và đơn vị trong tổ chức đều cũng có trách nhiệm trong việc phản ánh đến những người có trách nhiệm về những vấn đề liên quan đến $5 \mathrm{~S}$ tại các vị trí đó.

Thực hiện $5 \mathrm{~S}$ đồng nghĩa với việc cá nhân, tập thể đôi khi phải cương quyết loại bỏ những hành vi hay lối suy nghĩ đã trở thành thói quen trước đây. Việc này thực sự không hề dễ dàng khi mà những thói quen 
đó thường đã tồn tại khá lâu, nhận được sự đồng thuận của tập thể, mang suy nghĩ là đã khiến mọi người cảm thấy rất thuận tiện hay thoải mái. Thực hiện $5 \mathrm{~S}$ đồng nghĩa với việc giảm thiểu số lượng cũng như thu hẹp vị trí sử dụng của một số những vật dụng vốn đã quen thuộc đối với bản thân và mọi người ở cùng nơi làm việc. Cũng không hề dễ dàng khi yêu cầu mọi người sử dụng chung vật dụng mà trước đây mỗi cá nhân được quyền sử dụng riêng, hoặc yêu cầu mọi người di chuyển ra xa chỗ ngồi để thực hiện các hoạt động mà trước đây mỗi cá nhân chỉ cần ngồi một chỗ là có thể thực hiện được.

Loại bỏ những vật dụng không cần thiết hoặc đã được khẳng định là không cần thiết đôi khi không hẳn là dễ dàng do một số quy định hiện hành của tổ chức đòi hỏi phải có thời gian và quy trình tuân thủ. Tuy vậy, điều này không có nghĩa là $5 \mathrm{~S}$ chấp nhận tình trạng hiện diện của những vật dụng đã được xác định là không cần thiết tại nơi làm việc. Do đó, những vật dụng này cần được dán nhãn ghi rõ vị trí, công dụng và vai trò của chúng trong công việc hàng ngày tại nơi làm việc. Đồng thời, bố trí khu vực lưu trữ riêng ngay tại nơi làm việc để chờ đến hạn xử lý theo quy định và quy trình của tổ chức (ví dụ như hoạt động kiểm kê cuối năm, thanh lý cuối năm).

$5 \mathrm{~S}$ không chỉ có ý nghĩa và áp dụng đối với đồ vật, vật dụng, công cụ, thiết bị, v.v... mà $5 \mathrm{~S}$ còn liên quan và áp dụng cho việc quản lý hồ sơ giấy tờ cùng các thủ tục hành chính. Tương tự như nội dung $5 \mathrm{~S}$ áp dụng đối với vật dụng, $5 \mathrm{~S}$ cho hồ sơ tài liệu và thủ tục hành chính cũng gồm 5 nội dung, tuy không nhiều bằng nội dung $5 \mathrm{~S}$ cho vật dụng, bao gồm: Sàng lọc, Sắp xếp, Sạch sẽ, Săn sóc, và Sẵn sàng. Vai trò của $5 \mathrm{~S}$ cho hồ sơ tài liệu và thủ tục hành chính cũng quan trọng không kém so với vai trò của $5 \mathrm{~S}$ áp dụng đối với vật dụng và đóng góp vào sự thành công của hoạt động $5 \mathrm{~S}$ nói chung.

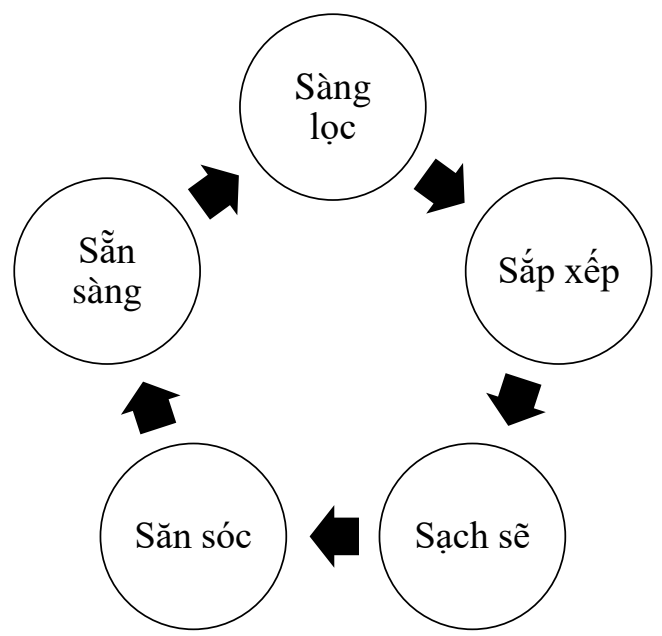

Hình 1: Nội dung thực hiện 5S

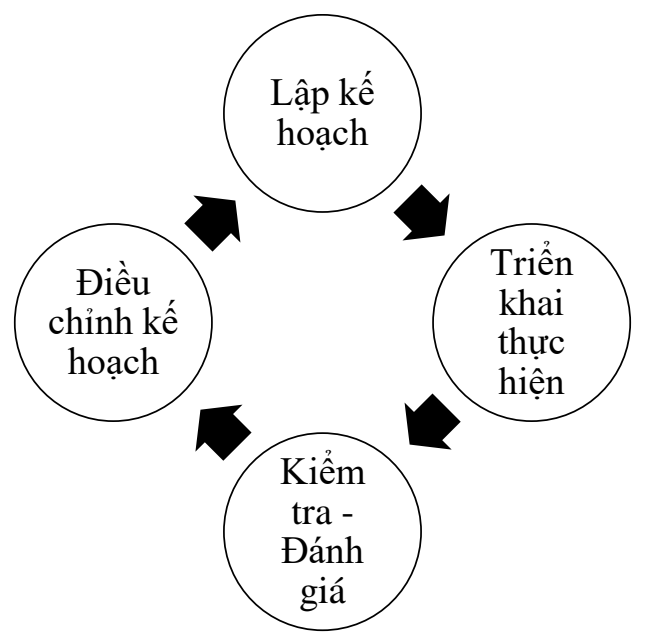

Hình 2: Quy trình PDCA thực hiện 5S

\section{$2.25 S$ đối với đồ vật}

$5 \mathrm{~S}$ là ký hiệu viết tắt của:

Seiri (Sàng lọc): Phân loại những đồ vật không cần thiết và tiến hành loại bỏ ra khỏi nơi làm việc

- Seiton (Sắp xếp): Bố trí, sắp đặt mọi thứ ngăn nắp để thuận tiện cho sử dụng và dễ dàng khi tìm kiếm

- Seiso (Sạch sẽ): Giữ gìn vệ sinh, máy móc, thiết bị để đảm bảo môi trường, mỹ quan tại nơi làm việc

- Seiketsu (Săn sóc): Thường xuyên thực hiện một cách đều đặn các hoạt động của nội dung $3 \mathrm{~S}$ trên

- Shitsuke (Sẵn sàng): Duy trì kết quả đã đạt được từ $4 \mathrm{~S}$ trên và cải tiến liên tục sao cho tốt hơn nữa

\subsubsection{Seiri (Sàng lọc)}

Sàng lọc đồ vật, vật dụng hay trang thiết bị, máy móc theo 4 tiêu chí thời gian hay tần suất sử dụng: đang sử dụng, thường xuyên sử dụng, ít khi sử dụng, và không sử dụng:

- $\quad$ Đang sử dụng (hàng ngày)

- $\quad$ Thường sử dụng

- $\quad$ Ít khi sử dụng

- $\quad$ Không sử dụng nữa 


\subsubsection{Seiton (Sắp xếp)}

Với việc việc phân loại thành 4 nhóm này, giải pháp áp dụng tương ứng sẽ là:

- Với nhóm đồ đang sử dụng: Đặt ở ngay trước mặt, trên bàn

- Với nhóm đồ thường xuyên sử dụng: Đặt trong tầm tay sử dụng

- V Với nhóm đồ ít khi sử dụng: Đặt kế bên, bên cạnh

- Với nhóm đồ không sử dụng: Đưa vào kho hay khu vực lưu trữ riêng hoặc hủy bỏ

Vị trí mỗi đồ vật, vật dụng, dụng cụ, máy móc thiết bị nên được đánh dấu bằng đường vạch chỉ dẫn. Việc này vừa có ý nghĩa lại vừa giúp:

- Xác định chính xác vị trí và tên gọi đồ vật khi cần đến

- Xác định tình trạng hiện hữu của đồ vật (còn hay mất)

- Xác định được vị trí tối ưu cũng như hạn chế của vị trí hiện tại

- Là bằng chứng minh họa cách thức quản lý khoa học của đơn vị

- Các chuyên gia cũng lưu ý:

- Hạn chế để các đồ vật ra ngoài khi đã có các tủ đựng; sử dụng tối đa không gian trong các tủ đựng

- Hạn chế treo tường các vật dụng không cần thiết, kể cả đồ trang trí trong phòng

- Không để các đồ vật có kích thước/trọng lượng lớn trên cao, đề phòng rơi vào người nguy hiểm

- Căn cứ vào hình dạng đồ vật sắp xếp sao cho hợp lý, dễ sử dụng, và đảm bảo tính thẩm mỹ

- Văn phòng làm việc nên bố trí khu vực "Hậu cần" riêng (bình nước uống, chỗ pha cà phê, v.v...)

- Dụng cụ, thiết bị văn phòng nên để tập trung để mọi người có thể chia sẻ sử dụng, tránh lãng phí

- Cung cấp đầy đủ tủ đựng đồ dùng cá nhân, tuy nhiên, hạn chế để đồ dùng cá nhân nhiều tại nơi làm

- Hạn chế dựng nhiều vách ngăn tại nơi làm; cố gắng tạo không gian mở để tăng cơ hội tiếp xúc

- Đối với các khu vực hạn chế hay có tính bảo mật cao, phải có biển báo và thiết lập chế độ an ninh

- Không đặt các đồ vật hay bố trí các tủ đựng, giá đỡ, v.v... gây cản trở hay che lấp lối thoát hiểm

\subsubsection{Seiso (Sạch sẽ)}

- Quét dọn, lau chùi thường xuyên các đồ vật, vật dụng, trang thiết bị, máy móc

- Một số vật dụng, trang thiết bị, máy móc có thể yêu cầu quy trình hay chất liệu làm sạch riêng

- Việc làm sạch đòi hỏi phải thực hiện có tính hệ thống và đồng bộ

Sạch sẽ bên cạnh lợi ích chính là đảm bảo môi trường làm việc sạch sẽ nhằm có lợi cho sức khỏe còn có các lợi ích khác như:

- Giúp trang thiết bị, máy móc vận hành tốt do bụi bẩn sẽ làm máy chạy chậm hoặc không chạy được.

- Phát hiện ra các hư hỏng hay hiện tượng bất thường trong vận hành máy móc hay sử dụng thiết bị

- Có khả năng tìm lại được đồ vật bị thất lạc

- Tăng cường tinh thần đoàn kết khi công tác được thực hiện một cách có tổ chức và huy động được mọi người cùng tham gia

Các chuyên gia cũng lưu ý:

- Đảm bảo vệ sinh cá nhân cũng là một trong những yêu cầu của Seiso

- Lắp đặt các thùng rác phân loại tại những nơi quy định, vừa đảm bảo sự thuận tiện vừa phải đảm bảo tính thẩm mỹ, tuy nhiên, cũng không nên lạm dụng đặt nhiều thùng tại nhiều nơi

\subsubsection{Seiketsu (Săn sóc)}

- Luôn để ý, quan tâm, và thực hiện các công tác sàng lọc, sắp xếp, và sạch sẽ đối với các đồ vật, vật dụng hay trang thiết bị, máy móc; không những của cá nhân mà còn của cả tập thể

- Thực hiện các công tác trên - sàng lọc, sắp xếp, và sạch sẽ - một cách thường xuyên và liên tục

- Nhắc nhở mọi người xung quanh cùng quan tâm và cùng thực hiện các công tác trên

- Ban hành quy định có tính nguyên tắc, đảm bảo công tác được thực hiện theo định kỳ, có sự kiểm soát thường xuyên ntừ người quản lý

- Tuyên truyền ý thức tiết kiệm, bảo vệ môi trường, tái chế nguyên vật liệu, tái sử dụng trang thiết bị

- Chú ý đến tính yếu tố tương lai và tính bền vững của các công tác

- Coi trọng nhưng không làm ảnh hưởng nhiều đển chức năng hay nhiệm vụ chính của tổ chức

\subsubsection{Shitsuke (Sã̃n sàng)}


- Thực hiện các công tác trên một cách thường xuyên và liên tục

- Giai đoạn đầu phải nghiêm túc thực hiện theo quy định của tổ chức

- $\quad$ Giai đoạn sau sẽ dần trở thành một thói quen, thành ý thức tự nguyện

- $\quad$ Ban đầu áp dụng đối với từng cá nhân, sau đó, với từng tập thể

- Chia sẻ những kinh nghiệm thực hiện với các cá nhân và đơn vị khác

- Luôn suy nghĩ tìm kiểm thêm các giải pháp nhằm cải thiện tốt hơn các kết quả đã đạt được

\section{3 $5 \mathrm{~S}$ đối với hồ so/giấy tờ/tài liệu}

5S là ký hiệu viết tắt của:

Seiri (Sàng lọc): Phân loại hồ sơ/giấy tờ/tài liệu không cần thiết và tiến hành loại bỏ ra khỏi nơi làm việc/quy trình thủ tục hành chính

- Seiton (Sắp xếp): Bố trí, sắp xếp hồ sơ/giấy tờ/tài liệu gọn gàng để thuận tiện cho sử dụng và dễ dàng khi tìm kiếm

- Seiso (Sạch sẽ): Vệ sinh lau chùi các kệ, tủ, hộp/khay đựng giấy tờ, v.v... đảm bảo không dính bụi

- Seiketsu (Săn sóc): Thường xuyên thực hiện một cách đều đặn các hoạt động của nội dung $3 \mathrm{~S}$ trên

- Shitsuke (Sẵn sàng): Duy trì kết quả đã đạt được từ $4 \mathrm{~S}$ trên và cải tiến liên tục cho tốt hơn nữa, trong đó bao gồm cả thủ tục hành chính

\subsubsection{Seiri (Sàng lọc)}

Xác định 4 nhóm hồ sơ/giấy tờ/tài liệu, theo 4 tiêu chí thời gian hay tần suất sử dụng:

- $\quad$ Đang sử dụng (hàng ngày)

- Thường sử dụng

- $\quad$ Ít khi sử dụng

- $\quad$ Không sử dụng nữa

\subsubsection{Seiton (Sắp xếp)}

Với việc phân loại hồ sơ/giấy tờ/tài liệu theo 4 tiêu chí này, giải pháp tương ứng áp dụng sẽ là:

- V Với hồ sơ/giấy tờ/tài liệu đang sử dụng: Đặt ở ngay trước mặt, trên bàn

- Với hồ sơ/giấy tờ/tài liệu thường xuyên sử dụng: Đặt trong tầm tay sử dụng

- Với hồ sơ/giấy tờ/tài liệu ít khi sử dụng: Đặt kế bên, bên cạnh

- Với hồ sơ/giấy tờ/tài liệu không sử dụng hay thủ tục hành chính không cần thiết: Đưa vào kho, khu vực lưu trữ riêng, hoặc hủy bỏ

- Vị trí mỗi hồ sơ/giấy tờ/tài liệu xếp theo chủng loại được đánh dấu bằng đường vạch chỉ dẫn

- Giấy tờ/tài liệu nên được sắp xếp vào các tập hồ sơ có nhãn dán đầy đủ các thông tin cần thiết

- Các tập hồ sơ, đến lượt chúng lại được sắp xếp vào các tủ, kệ có dãn nhán

- Thông tin trên nhãn dán hoàn toàn do cá nhân quản lý hay lãnh đạo đơn vị quyết định sao cho thuận tiện và giảm thiểu thời gian tìm kiếm khi cần đến

- Không có một mẫu nhãn thông tin chung nào cho tất các các loại hồ sơ giấy tờ.

- Có nhiều tiêu chí sắp xếp hồ sơ/giấy tờ/tài liệu, tuy vậy, một trong các tiêu chí phổ biến đó là sắp theo trình tự thời gian

Việc sắp xếp này có ý nghĩa:

- Xác định chính xác vị trí và tên gọi giấy tờ/tài liệu khi cần đến

- Xác định tình trạng hiện hữu của hồ sơ/giấy tờ/tài liệu (còn hay mất)

- Là bằng chứng minh họa cách thức quản lý khoa học của đơn vị

- Hạn chế để các giấy tờ, tài liệu ra ngoài khi đã có các tủ/kệ/giá/hộp đựng; sử dụng tối đa không gian trong các tủ/kệ/giá/hộp đựng để xếp giấy tờ, tài liệu vào

- Không để các hồ sơ, giấy tờ, tài liệu có kích thước hay trọng lượng lớn trên cao, đề phòng rơi vào người nguy hiểm

- Căn cứ vào hình dạng hồ sơ, giấy tờ, tài liệu sắp xếp sao cho hợp lý, dễ sử dụng, và đảm bảo tính thẩm mỹ

- Đối với các hồ sơ, giấy tờ, tài liệu được xếp vào loại mật, hạn chế tiếp cận, phải có khu vực riêng và thiết lập chế độ bảo mật

- Không đặt hồ sơ, giấy tờ, tài liệu gây cản trở lối đi hay lối thoát hiểm 
- Nếu cần thiết phải bố trí khu vực xử lý riêng đối với những hồ sơ/giấy tờ/tài liệu cần mặt bằng rộng hay phải sử dụng các dụng cụ văn phòng có kích cỡ lớn

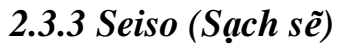

- Hút bưi, hút ẩm thường xuyên các hồ sơ, giấy tờ, tài liệu

- Một số loại hồ sơ, giấy tờ, tài liệu do chất liệu có thể yêu cầu quy trình hay hóa chất làm sạch riêng

- Việc làm sạch đòi hỏi phải thực hiện có tính hệ thống và đồng bộ

Sạch sẽ bên cạnh việc tạo môi trường làm việc sạch sẽ, có lợi cho sức khỏe còn có các lợi ích khác như:

- Giúp hồ sơ/giấy tờ/tài liệu không bị hư hại do ẩm mốc, bụi bẩn bám có thể gây tình trạng dính, rách

- Phát hiện ra các hồ sơ/giấy tờ/tài liệu bị rách, dính chung, v.v...

- Có khả năng tìm lại được hồ sơ/giấy tờ/tài liệu bị thất lạc

- Phát hiện ra các quy trình, thủ tục hành chính gây cản trở hay làm chậm quá trình xử lý thông tin

\subsubsection{Seiketsu (Săn sóc)}

- Luôn để ý, quan tâm, và thực hiện các công tác sàng lọc, sắp xếp, và sạch sẽ đối với các hồ sơ/giấy tờ/tài liệu; không những của cá nhân mà còn của cả tổ chức

- Thực hiện các công tác trên - sàng lọc, sắp xếp, và sạch sẽ - một cách thường xuyên và liên tục

- Nhắc nhở mọi người xung quanh cùng quan tâm và cùng thực hiện các công tác trên

- Tuyên truyền ý thức tiết kiệm giấy, bảo vệ môi trường, tái sử dụng giấy, tái chế giấy

\subsubsection{Shitsuke (Sã̃n sàng)}

- Luôn duy trì hồ sơ/giấy tờ/tài liệu trong tình trạng gọn gàng, ngăn nắp, sạch sẽ

- Luôn suy nghĩ tìm kiếm thêm các giải pháp nhằm cải thiện tốt hơn các kết quả đã đạt được

- Luôn chia sẻ những thành quả và kinh nghiệm thực hiện $5 \mathrm{~S}$ với những người khác

\subsection{Kiểm tra - Đánh giá trong thực hiện $5 \mathrm{~S}$}

Kiểm tra - Đánh giá là một khâu trong quy trình PDCA (xem Biểu đồ 2) áp dụng trong quá trình thực hiện $5 \mathrm{~S}$. Hoạt động kiểm tra - đánh giá việc thực hiện $5 \mathrm{~S}$ có nhiều mục đích và ý nghĩa:

- Là cách thức thể hiện sự hiện diện của hoạt động quản lý và kiểm soát của lãnh đạo đối với đơn vị

- Nhằm hoàn thành chu kỳ PDCA theo đúng nguyên tắc thực hiện

- Tìm ra sự khác biệt giữa thực tế thực hiện và kế hoạch đề ra ban đầu, bao gồm cả các mục tiêu

- Đề xuất các hướng hay giải pháp xử lý đối với những khác biệt này

- Nhìn nhận ra những tồn tại - khuyết điểm, đề xuất cổ vũ những tiến bộ - ưu điểm liên quan đến $5 \mathrm{~S}$

- Xác định người/đơn vị chịu trách nhiệm về những tồn tại cần khắc phục

- $\quad$ Yêu cầu người/đơn vị chịu trách nhiệm có giải pháp khắc phục với kế hoạch và thời gian biểu cụ thể kèm cam kết

- Các câu hỏi hay sử dụng khi kiểm tra: "Vật dụng này có cần thiết không", "Vị trí để này có phù hợp không", "Ai là người sử dụng"

- Lập kế hoạch kiểm tra: bố trí nhân sự, lên lịch, chuẩn bị máy chụp hình, các tiêu chí đánh giá

- Có thể xây dựng các tiêu chí riêng cho: văn phòng, xưởng thực hành, lớp học, khu vực công cộng

\section{TIẾN TRÌNH THỰC HIỆN}

Quá trình thực hiện $5 \mathrm{~S}$ tuân thủ theo Quy trình PDCA. Trong hoạch định, trước khi đi đến bản kế hoạch cuối cùng, các chuyên gia đều tham khảo ý kiến của lãnh đạo nhà trường cùng với việc thảo luận các nội dung chi tiết với lãnh đạo các đơn vị liên quan. Giai đoạn này mất một khoảng thời gian tương đối vì các hoạt động bao gồm cả việc các chuyên gia Nhật giải thích về triết lý, khái niệm, và ý nghĩa của các nội dung về $5 \mathrm{~S}$ về lý thuyết và chuyển đổi thành các nội dung về $5 \mathrm{~S}$ trong thực tế áp dụng tại đơn vị. Kế hoạch sau khi được các bên thông qua sẽ được triển khai thực hiện ngay thông qua việc nhà trường ban hành các văn bản, quyết định triển khai thực hiện Dự án theo kế hoạch. Giai đoạn triển khai thực hiện là giai đoạn chính và chiếm phần lớn thời gian triển khai Dự án. Đây cũng là giai đoạn phát sinh nhiều vấn đề nhất, phản ánh thực tế áp dụng $5 \mathrm{~S}$ kèm theo các phản hồi từ các đơn vị và cá nhân tham gia. Những khác biệt giữa lý thuyết $5 \mathrm{~S}$ và thực tế áp dụng được thể hiện thông qua giai đoạn Kiểm tra - Đánh giá. 
Bên cạnh các đợt kiểm tra đánh giá nội bộ trong trường, có 2 đợt kiểm tra toàn diện (giữa kỳ và cuối kỳ) được thực hiện bởi đoàn đánh giá Nhật Bản với thành phần là các giảng viên Kosen, chuyên gia và đại diện JICA. Kết quả kiểm tra đánh giá được đoàn báo cáo với JICA, Bộ Công Thương, lãnh đạo nhà trường và thông báo tới các đơn vị thụ hưởng. Kết thúc Dự án, các kết luận kiểm tra đánh giá đa phần ghi nhận tích cực hiệu quả thực hiện Dự án tại các đơn vị, bên cạnh đó, là một số lưu ý về những tổn tại cần được các đơn vị tiếp tục khắc phục trong thời gian tới.

\section{KẾT QUẢ THỰC HIỆN}

Kết thúc Dự án, các đơn vị thụ hưởng đã thu được nhiều kết quả tích cực từ việc áp dụng $5 \mathrm{~S}$ :

Văn phòng làm việc, phòng học, phòng thí nghiệm, khu vực kho - xưởng, hành lang trong các tòa nhà, nhà vệ sinh, sân trường đều rất sạch sẽ; đồ dùng, đồ nội thất, phương tiện và công cụ làm việc được bố trí gọn gàng ngăn nắp, có tính khoa học và hợp lý

Mọi người, từ lãnh đạo đến nhân viên và người học đều luôn có ý thức quan tâm việc thực hiện $5 \mathrm{~S}$ trong công việc, không chỉ tại đơn vị mình mà còn cả các đơn vị khác và trong toàn trường

Thực hiện $5 \mathrm{~S}$ đang dần trở thành một trong những nét nổi bật của văn hóa $\mathrm{IUH}$, là niềm tự hào của nhà trường, và cũng trở thành một trong các điểm mạnh của nhà trường trong quá trình tham gia các chương trình kiểm định chất lượng giáo dục đào tạo sau này.

\section{BÀI HỌC KINH NGHIỆM}

Những bài học kinh nghiệm rút ra sau khi kết thúc Dự án:

- Nhân viên ngại thay đổi vì những thói quen đã hình thành từ lâu và duy trì trong một thời gian dài

- Không có một tài liệu chính thức mang tính chuẩn hóa để hướng dẫn về cách thực hiện $5 \mathrm{~S}$

- Nhận thức sơ sài về $5 S$ dẫn đến việc thực hiện qua loa, mang tính đối phó với lãnh đạo, tổ chức

- Quá đề cao vai trò của $5 \mathrm{~S}$ dẫn đến ảnh hưởng nhiều đến nhiệm vụ hay công tác chính của tổ chức

- Chỉ có lãnh đạo ủng hộ, hoặc chỉ có giảng viên quyết tâm, hoặc chỉ có sinh viên thực hiện

- Việc thực hiện vướng một số quy định có tính chất vĩ mô, liên quan đến cơ quan quản lý cấp trên

- Thiếu sự thống nhất về cách thức thực hiện giữa các cá nhân trong đơn vị hay giữa các đơn vị

- Thiếu sự động viên, khuyến khích có tính kịp thời, thường xuyên, ghi nhận xứng đáng từ lãnh đạo

- Khó duy trì được thành quả đạt được trong thời gian dài nếu lãnh đạo thiếu quan tâm thường xuyên

\section{KẾT LUẬN}

Việc thực hiện $5 \mathrm{~S}$, theo các chuyên gia Nhật Bản, không phải là điều gì quá cao siêu, quá khó khăn, quá phiền phức, hay quá tốn kém. Những thành quả to lớn đạt được sau khi thực hiện $5 \mathrm{~S}$ đều bắt nguồn từ những thay đổi nhỏ nhất mang tính tích cực. Sự đóng góp của từng cá nhân là nhân tố quyết định đến thành công của toàn tổ chức. Mục đích cuối cùng mà $5 \mathrm{~S}$ hướng tới không phải vì một danh hiệu hay một phần thưởng cho tổ chức, mà chính là việc tạo ra một môi trường làm việc được bố trí khoa học, có lợi cho sức khỏe, từ đó góp phần nâng cao năng suất lao động của mọi người trong tổ chức. Quá trình triển khai thực hiện đòi hỏi sự đồng tâm nhất trí của toàn thể các thành viên trong tổ chức. Trong Dự án JICAIUH, đó là sự quyết tâm của Ban giám hiệu nhà trường; là ý thức và sự tự giác của toàn thể công chức viên chức, giảng viên và sinh viên; là kế hoạch triển khai mô hình đào tạo Kosen; là sự phối hợp giữa các phòng ban chức năng, các khoa, viện, trung tâm, các cơ sở; là các chuyển gia Nhật Bản đến từ các trường Kosen và Cơ quan Hợp tác quốc tế Nhật Bản (JICA). Cuối cùng, $5 \mathrm{~S}$ chỉ thực sự thành công và có ý nghĩa khi những kết quả tích cực của $5 \mathrm{~S}$ được duy trì ổn định và thường xuyên về sau.

\section{TÀI LIỆU THAM KHẢO}

[1] Hayashida, T. (2013-2017). Tài liệu 5S. Dự án JICA-IUH, Đại học Công nghiệp TP. Hồ Chí Minh.

[2] Hayashida T. (2017). Ý nghĩa mô hình đào tạo Kosen. Hội thảo về Mô hình Kosen tại Đại học Công nghiệp TP. Hồ Chí Minh. 
[3] Dự án JICA-IUH (2017). Tài liệu tập huấn mô hình đào tạo Kosen (2013-2017). Đại học Công nghiệp thành phố Hồ Chí Minh.

[4] Khoa Công nghệ Hóa học (2017). Báo cáo thường niên tiến độ thực hiện Dự án JICA-IUH, Đại học Công nghiệp TP. Hồ Chí Minh.

[5] Khoa Công nghệ Cơ khí (2017). Báo cáo thuoơng niên tiến độ thực hiện Dự án JICA-IUH, Đại học Công nghiệp TP. Hồ Chí Minh.

[6] Khoa Kế toán - Kiểm toán (2016). Báo cáo thưc hiện 5S, Đại học Công nghiệp thành phố Hồ Chí Minh.

[7] Đại học Công nghiệp TP. Hồ Chí Minh (2017). Tài liệu hội thảo về Mô hình Kosen.

[8] Ricoh (4/2017). Ricoh Japan's activities for 5S.

[9] Ibaraki College (10/2017). Một số hình ảnh về truờng Ibaraki College, Chuyến công tác 10/2017

Ngày nhận bài: 04/12/2017

\section{Phụ lục1: Nhũ̃ng tồn tại trước khi thực hiện 5S}

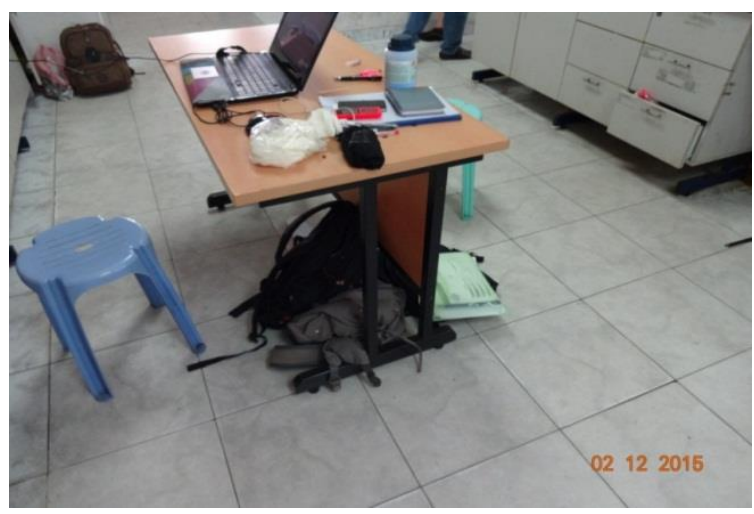

Hình 1: Bừa bộn trên và dưới mặt bàn làm việc (Nguồn: Hayashida, 2017)

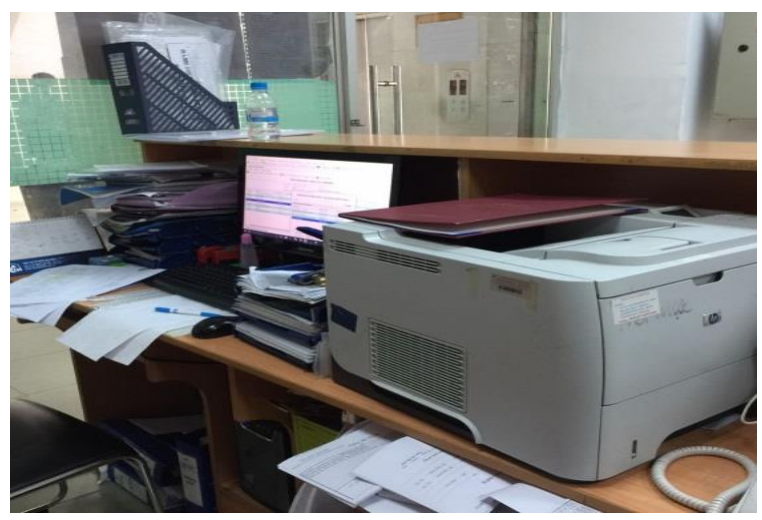

Hình 3: Thiết bị văn phòng để chung giấy tờ (Nguồn: Khoa KT-KT, 2017)

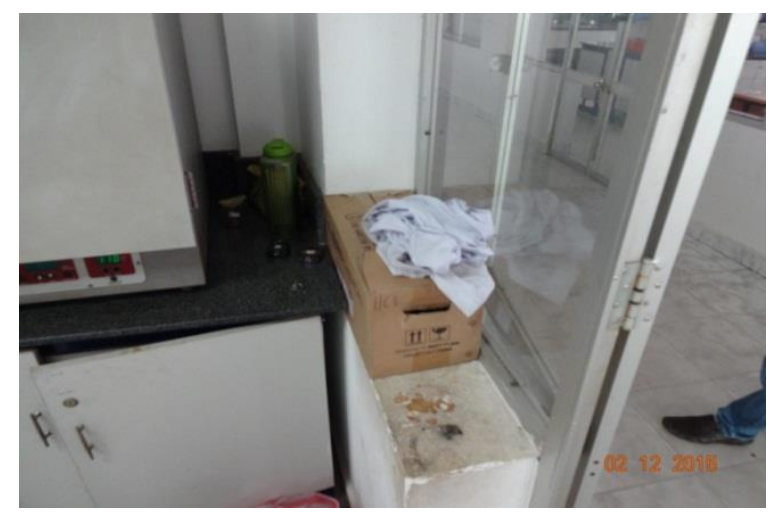

Hình 2: Vật dụng không rõ mục đích sử dụng (Nguồn: Hayashida, 2017)

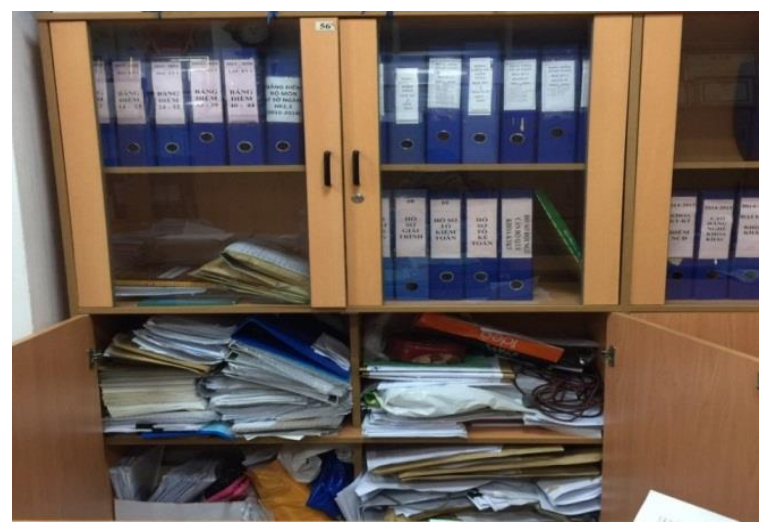

Hình 4: Tủ đựng hồ sơ sắp xếp lộn xộn (Nguồn: Khoa KT-KT, 2017)

\section{Phụ lục 2: Khắc phục sau khi thực hiện $5 \mathrm{~S}$}




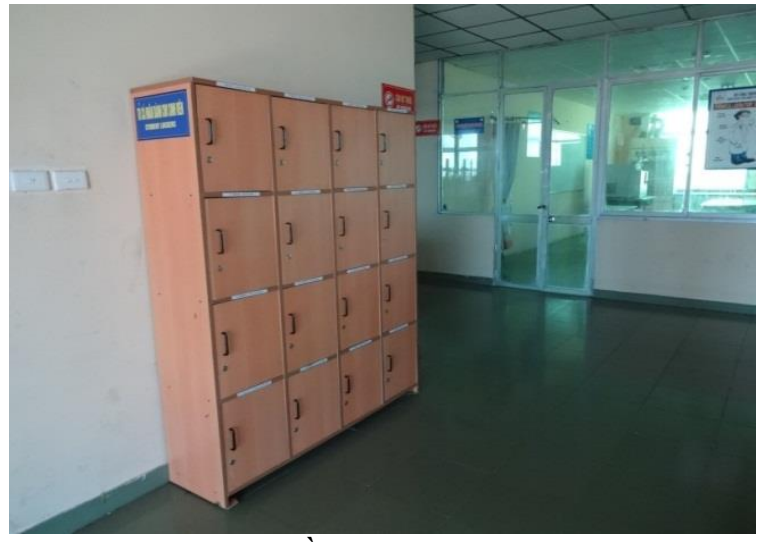

Hình 5: Tủ đựng đồ trước phòng thí nghiệm (Nguồn: Hayashida, 2017)

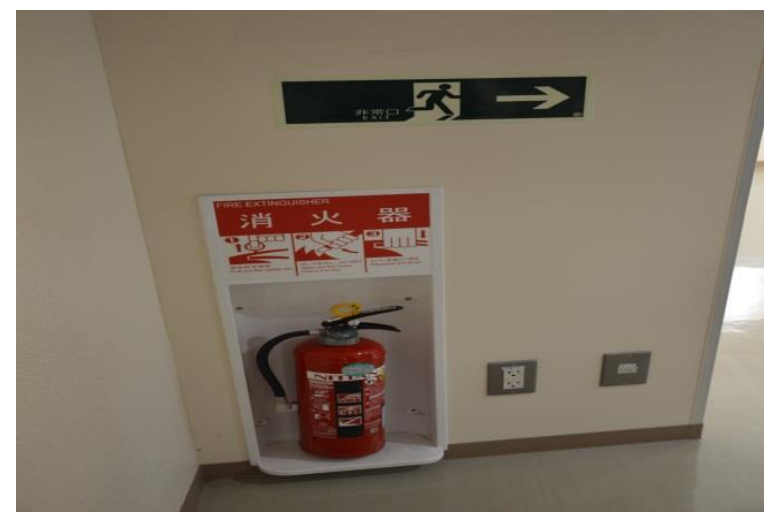

Hình 7: Tủ đựng Bình chữa cháy với bảng hiệu (Nguồn: Ibaraki College, 2017)

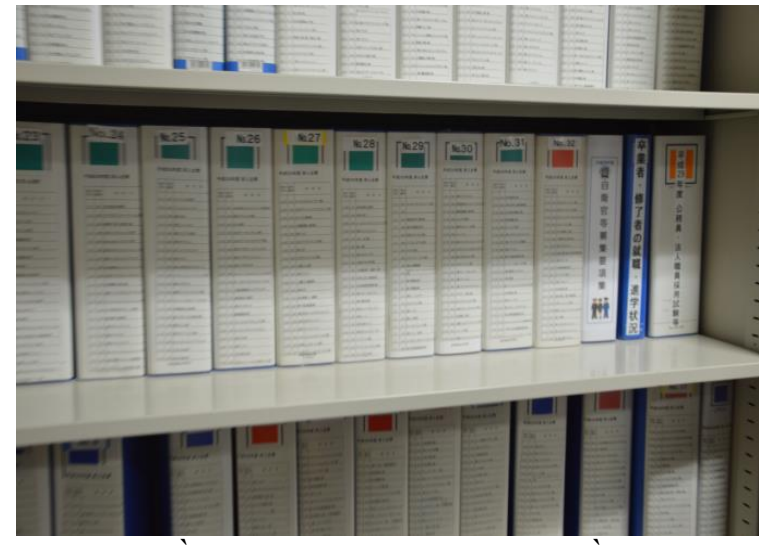

Hình 6: Hồ sơ lưu trữ với nhãn dán đầy đủ (Nguồn: Ibaraki College, 2017)

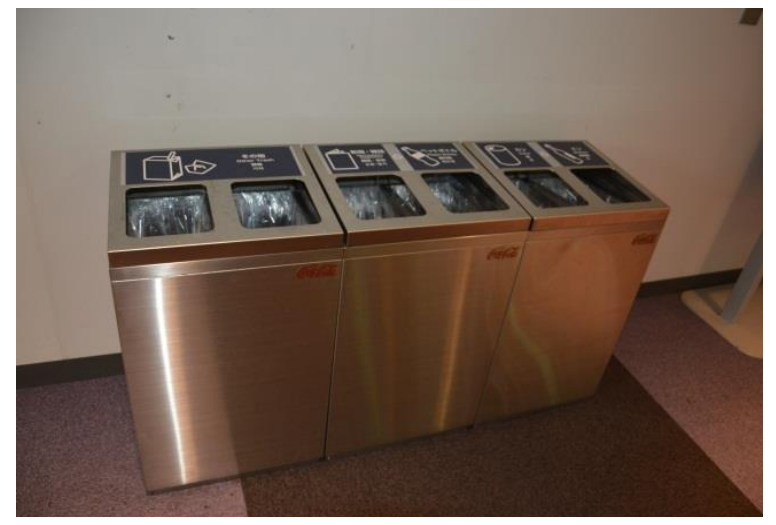

Hình 8: Thùng rác phân loại để tập trung 1 chỗ (Nguồn: Ibaraki College, 2017) 